\title{
DINAMIKA KESEPAKATAN PERDAGANGAN LINTAS BATAS ANTARA INDONESIA DAN MALAYSIA DAN PENGEMBANGAN SENTRA KELAUTAN DAN PERIKANAN TERPADU (SKPT) SEBATIK DI KALIMANTAN UTARA
}

\section{The Dynamics of Border Trade Agreement between Indonesia - Malaysia and the Development Integrated Fishery Center (SKPT) Sebatik in North Kalimantan}

\author{
*Bayu Vita Indah Yanti dan Umi Muawanah \\ Balai Besar Riset Sosial Ekonomi Kelautan dan Perikanan \\ Gedung BRSDM KP I Lt. 4, Jalan Pasir Putih Nomor 1 Ancol Timur, Jakarta Utara, Indonesia \\ Telp: (021) 64711583 Fax: 64700924 \\ Diterima tanggal: 20 November 2019; Diterima setelah perbaikan: 5 Mei 2020; \\ Disetujui terbit: 25 Juni 2020
}

\begin{abstract}
ABSTRAK
Perdagangan lintas negara Malaysia - Indonesia telah berlangsung lebih dari 30 tahun sejak tahun 29170 dengan payung hukum kesepakatan perdagangan lintas negara (The Border Trade Agreement (BTA) Between the Government of the Republic of Indonesia and the Government of Malaysia). Pada tahun 2015, pemerintah melalui Kementerian Kelautan dan Perikanan (KKP) memiliki kebijakan khusus untuk pengembangan ekonomi wilayah perbatasan pembangunan Sentra Kelautan dan Perikanan Terpadu (SKPT) di pulau-pulau kecil dan terluar. Pulau Sebatik merupakan salah satu lokasi perbatasan yang sangat strategis untuk dikembangkan dan karena alasan tersebut, lokasi ini menjadi salah satu lokasi dari SKPT. Pembangunan SKPT Sebatik secara tidak langsung diperkirakan dapat menimbulkan dampak terhadap perkembangan kerjasama sosial ekonomi Malaysia -Indonesia (Malindo), karena pembangunan SKPT memunculkan pusat pertumbuhan ekonomi baru di wilayah perbatasan Malindo. Tujuan paper ini membahas pengaruh Pengembangan SKPT Sebatik terhadap dinamika kesepakatan kerjasama perdagangan lintas batas Indonesia dan Malaysia. Penelitian menggunakan metode kualitatif dengan menganalisa data primer dan sekunder yang bersumber pada observasi lapangan, wawancara dan dokumen-dokumen kesepakatan kerjasama. Kajian menemukan bahwa kebijakan pembangunan dan pengembangan SKPT Sebatik diperkirakan akan memberikan pengaruh positif terhadap kerjasama perdagangan lintas batas Indoensia Malayasi yang selanjutnya lebih dikenal Sosek Malindo. Pengembangan SKPT akan meningkatkan nilai tawar posisi Indonesia dalam perundingan kerjasama sosial ekonomi Indonesia-Malaysia khususnya terkait perdagangan produk hasil perikanan lintas negara Indonesia dan Malaysia.
\end{abstract}

Kata Kunci: perdagangan perbatasan; sosek malindo; SKPT; Sebatik; perikanan

\begin{abstract}
Cross-country trade agreement between Malaysia-Indonesia has lasted more than 30 years since 1970s under The Border Trade Agreement (BTA) Between the Government of the Republic of Indonesia and the Government of Malaysia. In 2015, the government of Indonesia through the Ministry of Marine Affairs and Fisheries (KKP) had a policy for the economic development of the border areas for the development of the Integrated Marine and Fisheries Center (SKPT) on small and outermost islands. Sebatik Island is a very strategic border location to be. Therefore, Sebatik was chosen as one of the locations of the SKPTs. The Sebatik SKPT development will indirectly influence the development of Malaysian-Indonesian (Malindo) socio-economic cooperation. the SKPT development raises a new economic growth center in the Malindo border region. The purpose of this paper is to discuss the effect of the Development of Sebatik SKPT on the dynamics of cross-border trade agreements between Indonesia and Malaysia. The study uses qualitative method by analyzing primary and secondary data sourced from field observations, interviews and cooperation agreement documents. The study found that the development policy of the SKPT Sebatik is expected to have a positive influence on the cross-border Indonesian trade cooperation between Malaysia and Indonesia, which is later known as Sosek Malindo. The development of the SKPT will increase the bargaining value of Indonesia's position in the Indonesia-Malaysia socio-economic cooperation negotiations, especially related to the trade of fishery products across Indonesia and Malaysia.
\end{abstract}

Keywords: border trade; sosek malindo; SKPT; Sebatik; fisheries 


\section{PENDAHULUAN}

Pulau Sebatik merupakan salah satu wilayah perbatasan Indonesia-Malaysia, di Kabupaten Nunukan, Provinsi Kalimantan Utara (Kaltara). Pulau ini mempunyai keunikan yaitu 1 pulau terdiri dari 2 (dua) wilayah negara berbeda yaitu Indonesia dan Malaysia. Kondisi ini menjadikan Sebatik sebagai salah satu wilayah perbatasan yang memiliki aktifitas perdagangan lintas negara secara tradisional, dan telah telah terjadi secara turun-temurun kurang lebih sejak 30 tahun yang lalu. Aktivitas ini telah menyumbangkan pertumbuhan ekonomi wilayah, pendapatan masyarakat, penyerapan tenaga kerja, dan devisa negara. Aktivitas perdagangan lintas batas ini memanfaatkan sumber daya alam seperti perkebunan, perikanan dan pariwisata. Pemasaran hasil sumber daya alam dari Sebatik biasanya lebih tinggi harganya dan lebih dekat dari Sebatik untuk dipasarkan ke Tawau, Negara Bagian Sabah, Malaysia.

Perdagangan lintas batas IndonesiaMalaysia telah dilegalkan melalui kesepakatan "The Border Trade Agreement Between the Government of the Republic of Indonesia and the Government of Malaysia" yang ditandatangani pada tanggal 24 Agustus 1970. Kebijakan ini menjadi salah satu materi muatan yang diatur dalam Undang-Undang Republik Indonesia Nomor 7 Tahun 2014 (UU RI No.7 Tahun 2014) tentang Perdagangan, terutama pada Pasal 55 dan Pasal 56. Ketentuan ini menyatakan perdagangan di wilayah perbatasan dapat dilakukan sesuai ketentuan perundang-undangan dengan persyaratan dilakukan oleh penduduk yang tinggal di wilayah perbatasan, kegiatan perdagangan hanya dilakukan pada wilayah tertentu yang telah ditetapkan, dan sesuai dengan perjanjian bilateral yang telah disepakati antarnegara perbatasan. Perdagangan lintas batas ini telah mengalami perubahan-perubahan sejak tahun 1970. Perubahan tersebut juga akan dipengaruhi oleh adanya pembangunan Sentra Kelautan dan Perikanan (SKPT) Sebatik saat ini yang dilakukan oleh Kementerian Kelautan dan Perikanan (KKP).

Program SKPT Sebatik dimulai sejak tahun 2015 sebagai program prioritas KKP untuk membangun daerah perbatasan. Kabupaten Nunukan menjadi salah satu lokasi dari 20 SKPT, dan lokasi SKPT tersebut berada di wilayah Sebatik. Pada pelaksanaan program ini, pemerintah pusat (dalam hal ini KKP) telah melaksanakan program pembangunan infrastruktur, program bantuan kapal dan alat tangkap dan kegiatan asistensi serta pendampingan kepada masyarakat perikanan pada beberapa lokasi di Kabupaten Nunukan yang merupakan bagian dari kawasan SKPT Nunukan di Pulau Sebatik. Pelaksanaan program SKPT akan mempengaruhi dinamika kesepakatan perdagangan antara Indonesia dan Malaysia.

Kebijakan pembangunan SKPT merupakan salah satu upaya mengubah paradigma pengelolaan kawasan perbatasan di masa lampau sebagai "halaman belakang" wilayah Indonesia, menjadi paradigma pengelolaan perbatasan sebagai "teras/beranda depan" wilayah Indonesia. Pilihan kebijakan wilayah perbatasan ini sejalan dengan pemikiran Utomo dalam Mira, Solihin, \& Tajerin (2013), dimana kebijakan memperbaharui wajah perbatasan tidak dapat diklasifikasikan sebagai kebijakan pembangunan yang normal. Sebaliknya, kebijakan tersebut harus diposisikan sebagai kebijakan khusus dalam rangka mengejar ketertinggalan pembangunan di semua bidang. Pembangunan di wilayah perbatasan pulau Sebatik sejalan dengan pemikiran Koespramoedyo, Sri, Aulia, Moris, Amril, \& Fauzan (2003), dimana pembangunan di Pulau Sebatik dapat menjadi pusat aktivitas perdagangan dengan interaksinya paling besar, baik dalam usaha perdagangan lintas tenaga kerja, maupun dalam hubungan sosial dan kekerabatan.

Berdasarkan pada uraian tersebut di atas, tulisan ini membahas kebijakan pengembangan SKPT Sebatik yang berpotensi mempengaruhi dinamika pelaksanaan kerjasama sosial ekonomi Malaysia-Indonesia. Secara lebih rinci, tulisan ini akan membahas: 1) Kebijakan Pengembangan SKPT Sebatik di Nunukan, 2) dinamika kesepakatan perdagangan lintas batas antara Indonesia Malaysia dan 3) Dinamika BCA dan BTA dan pengaruh SKPT Sebatik. Pembahasan ini penting karena temuan yang muncul berdasarkan penelitian akan menjadi bahan masukan untuk pembuat kebijakan dalam penguatan dan evaluasi pelaksanaan kerjasama sosial ekonomi Indonesia-Malaysia.

Penelitian ini menggunakan metode penelitian kualitatif, dengan pendekatan kualitatif, dengan menggunakan hasil kegiatan penelitian di SKPT Sebatik, untuk selanjutnya dianalisis secara deskriptif kualitatif (Alwasilah, 2011). 
Penelitian dilakukan di lokasi SKPT Sebatik Kabupaten Nunukan, Provinsi Kalimantan Utara pada tahun bulan Mei, September dan Oktober 2018. Data dan informasi yang digunakan terkait perkembangan kebijakan perjanjian perdagangan lintas batas antara Indonesia-Malaysia hingga saat ini, baik dalam bentuk peraturan, hasil-hasil kajian ilmiah sebelumnya, dan perkembangan pertemuan terakhir kelompok kerja Sosek Malindo. Berdasarkan data dan informasi tersebut, maka akan dilakukan analisis secara kualitatif untuk membahas bagaimana pembangunan SKPT Sebatik di Nunukan akan mempengaruhi kesepakatan perdagangan antar batas antara Indonesia dan Malaysia.

\section{KEBIJAKAN PEMBANGUNAN WILAYAH PERBATASAN DI SEBATIK, NUNUKAN}

Kebijakan pembangunan wilayah perbatasan dengan pendekatan kesejahteraan (prosperity approach) pada dasarnya merupakan upaya yang dilakukan berdasarkan pengembangan kegiatan ekonomi dan perdagangan untuk meningkatkan kesejahteraan masyarakat di kawasan perbatasan; dimana pengembangan aktivitas ekonomi dan perdagangan diarahkan untuk meningkatkan kualitas produk komoditas unggulan sehingga mempunyai daya saing di pasar internasional. Pendekatan ini merupakan konsekuensi logis dari paradigma baru dalam pengembangan kawasan perbatasan yang bergeser arah dari orientasi inward looking menjadi outward looking, sehingga kawasan perbatasan dapat dimanfaatkan sebagai pintu gerbang bagi aktivitas ekonomi dan perdagangan dengan negara tetangga. Hal ini berbeda dengan kebijakan yang dilakukan dengan pendekatan keamanan (security approach), dimana posisi kawasan perbatasan yang terletak berdampingan dengan negara tetangga baik darat maupun laut, menjadikan kawasan perbatasan rentan terhadap pelanggaran kedaulatan oleh negara lain. Oleh karena itu dibutuhkan pengawasan yang ketat agar keamanan nasional tetap terjaga (Sudiar, 2015).

Pada kasus Sebatik, pelaksanaan kebijakan khusus di wilayah perbatasan Pulau Sebatik salah satunya diwujudkan melalui program pembangunan Sentra Kelautan dan Perikanan Terpadu (SKPT). Pola pengelolaan kawasan perbatasan tidak hanya dilakukan dengan pendekatan pertahanan dan keamanan negara (Hankam), tetapi melalui pengelolaan kawasan perbatasan dengan pendekatan kesejahteraan melalui Pembangunan Pusat Pertumbuhan Ekonomi. Pemerintah pusat (melalui Kementerian Kelautan dan Perikanan (KKP)) melaksanakan pembangunan dan pengembangan SKPT untuk peningkatan perekonomian masyarakat perbatasan di beberapa wilayah perbatasan dan pulau-pulau kecil dan terluar, dan salah satunya ada pada kawasan Pulau Sebatik.

Posisi Sebatik pada perencanaan nasional, merupakan kawasan dengan potensi yang besar baik dari sumber daya alam (perkebunan dan perikanan) maupun posisi strategis sebagai pemasok makanan ke Tawau Malaysia. Akan tetapi, Sebatik belum terlihat secara mandiri sebagai sebuah entitas yang disebutkan dalam agenda nasional, lokasi ini masih menjadi prioritas sebagai bagian dari kabupaten Nunukan, padahal Sebatik merupakan lokasi prioritas pengembangan kawasan perbatasan (Wahyuni dan Kusumaningrum, 2016). Jika melihat dari sisi permasalahan perekonomian wilayah perbatasan (dalam hal ini Sebatik), sangat dipengaruhi oleh negara tetangga. Hal ini dikarenakan wilayah negara tetangga kondisinya jauh lebih maju jika dibandingkan dengan kondisi perekonomian di wilayah perbatasan Indonesia. Selain dikarenakan kondisi negara tetangga lebih baik, aksesibilitas relatif lebih mudah ke negara tetangga dibandingkan ke pulau utama (main land) yang terdekat di Indonesia (Mira et al., 2013).

Hasil penelitian Chairil, Sutiadi, \& Epin (2019), terdapat beberapa persoalan yang muncul di wilayah perbatasan Indonesia-Malaysia di Pulau Sebatik. Kesatu, tingginya penyelundupan narkotika terutama melalui jalur-jalur tikus, hal ini terjadi karena minimnya pengawasan yang disebabkan kurangnya jumlah personil keamanan (TNI dan Polri) yang bertugas di wilayah perbatasan. Kedua, kebijakan ekonomi belum sepenuhnya berpihak pada wilayah perbatasan di Pulau Sebatik, dimana untuk memenuhi kebutuhan hidup sehari-hari, masyarakat masih bergantung ke Malaysia; dan untuk mengatasi persoalan kedua, pemerintah perlu mengambil kebijakan khusus untuk masyarakat di wilayah perbatasan, misalnya; subsidi harga bahan makanan pokok, sehingga masyarakat memilih untuk membeli produk dalam negeri dibandingkan ke luar negeri (Malaysia). Kebijakan khusus tersebut dapat membuat masyarakat yang tinggal di perbatasan Pulau Sebatik merasa diperhatikan oleh negara, karena masih banyak kebutuhan pokok masyarakat diperoleh dari negara. Ketiga, berkaitan dengan ideologi, potensi lunturnya kebanggaan terhadap 
Indonesia di daerah perbatasan sangat tinggi. Hal ini disebabkan karena masih banyak masalah pemenuhan kebutuhan hidup yang belum terselesaikan. Persoalan di hampir seluruh wilayah perbatasan selama ini tidak jauh dari persoalan ekonomi yang belum terselesaikan. Jika tidak segera dicarikan solusi, lambat laun dapat mengikis nasionalisme dan rasa bangga terhadap Indonesia bagi masyarakat yang tinggal di wilayah perbatasan. Desakan kebutuhan ekonomi mendorong para pekerja dari Indonesia untuk berbondong-bondong pindah ke Malaysia, karena secara ekonomi Malaysia lebih menggiurkan dibandingkan Indonesia. Perencanaan yang matang dan terintegrasi diperlukan dalam mengatasi segala permasalahan yang terjadi di wilayah perbatasan yang dalam praksisnya melibatkan seluruh stakeholder intansi Pemerintahan Indonesia maupun pihak negara tetangga dengan melibatkan masyarakat sebagai aktor utamanya dalam upaya menguatkan keamanan di wilayah perbatasan. Selain itu, di era kemajuan teknologi informasi yang semakin masif saat ini, maka perlu dirancang suatu model pengamanan perbatasan melalui pemanfaatan teknologi yang berkelindan dengan system sosial budaya yang berkembang di lingkungan masyarakat. Model keamanan yang dilakukan tidak hanya hard-power dan soft-power, melainkan smart-power yakni kolaborasi antara prosperity approach dengan security approach melalui sinergi pentahelix (pemerintah, akademisi, sektor swasta, masyarakat, dan media)

Pendekatan pemerintah saat ini, dengan adanya pembangunan SKPT Sebatik, merupakan salah satu upaya tegas untuk melakukan pembangunan wilayah perbatasan dengan serius, dengan mengusung Nawacita ketiga, membangun Indonesia dari pinggiran. Sesuai dengan salah satu arah kebijakan pembangunan yaitu mewujudkan pembangunan yang merata dan dapat dinikmati seluruh komponen bangsa di berbagai wilayah Indonesia termasuk perbatasan (Warta Kementerian Perdagangan RI, 2016).

\section{DINAMIKA KESEPAKATAN PERDAGANGAN INDONESIA MALAYSIA}

Pada saat ini, implementasi kerjasama bilateral antara pemerintah Indonesia dengan Malaysia mengenai perbatasan sampai saat ini masih tetap berjalan dengan baik dan lebih banyak dilakukan dalam kerangka kerjasama bilateral dengan sosial ekonomi (sosek) Malindo.
Sosek Malindo merupakan kerjasama di bidang sosial ekonomi yang dilandasi oleh latar belakang politis mengenai wilayah perbatasan Malaysia (Serawak dan Sabah) dengan Indonesia (Kalimantan Barat, Kalimantan Timur, dan Kalimantan Utara). Forum Sosek Malindo mengadakan pertemuan setahun sekali dengan tempat saling bergantian antara Indonesia dan Malaysia. Sosek Malindo diketuai oleh General Border Committee (GBC) di masing-masing negara dan untuk Indonesia Ketua GBC adalah Panglima TNI; dibawah GBC telah dibentuk pula kelompok kerja (KK) Sosek Malindo di tingkat provinsi/negeri yang ditujukan untuk:

1. Menentukan proyek-proyek pembangunan sosial ekonomi yang digunakan bersama.

2. Merumuskan hal-hal yang berhubungan dengan pelaksanaan pembangunan sosial ekonomi di wilayah perbatasan.

3. Melaksanakan pertukaran informasimengenai proyek-proyek pembangunan sosial ekonomi di wilayah perbatasan bersama.

4. Menyampaikan laporan kepada KK Sosek Malindo tingkat pusat mengenai pelaksanaan kerjasama pembangunan sosial ekonomi di wilayah perbatasan.

Selain dikoordinasikan oleh Panglima TNI selaku ketua GBC Indonesia, KK Sosek Malindo juga melibatkan Menteri Luar Negeri masingmasing negara selaku ketua Joint Committee Meeting (JCM) dan Menteri Dalam Negeri Republik Indonesia untuk membicarakan pembicaraan kerjasama bilateral dan pengembangan wilayah perbatasan Kalimantan antara pemerintah Malaysia dan pemerintah RI (Koespramoedya, et. al. 2003).

Kerjasama Sosek Malindo adalah kesepakatan antara Indonesia dan Malaysia yang memfokuskan pada pengembangan bidang sosial-ekonomi di area perbatasan. Tujuan utama dari kerjasama ini adalah untuk meningkatkan kesejahteraan rakyat yang tinggal di area perbatasan di masing-masing negara. Kerjasama ini menghasilkan beberapa kesepakatan, namun tidak semuanya bisa dilaksanakan karena masalah penyesuaian. Kegagalan itu disebabkan oleh beberapa faktor, antara lain kewenangan terbatas aktor, faktor kepentingan dalam mengatur kerjasama dan tidak menggunakan metode persuasif. Terlebih lagi terdapat dampak serius terhadap pelaksanaan perjanjian dan prilaku aktor (Sudiar, 2014). 
Tabel 1. Dinamika Kesepakatan Perdagangan Lintas Batas Wilayah Perbatasan (KalimantanMalaysia).

Table 1. Dynamics Agreement Trading in Indonesia's Border (Kalimantan-Malaysia).

Periode/Period
$\begin{gathered}\text { Payung Hukum/Legal Based } \\ \text { Persyaratan tertentu /Special } \\ \text { Requirements) }\end{gathered}$

Siapa saja dapat melakukan transaksi perdagangan /Anyone can do trade transactions

Tidak memerlukan dokumen untuk keluar - masuk kawasan Indonesia Malaysia IDoes not require special documents to enter and exit the IndonesiaMalaysia border region

Perdagangan dengan transaksi barter /Trading is carried out with a barter system

Era sebelum Th.1970 /Before 1970

Bebas keluar-masuk kawasan Indonesia - Malaysia di seluruh wilayah

Belum ada /None perbatasan IFree to go in and out of Indonesia - Malaysia region in all border areas

Belum ada /None

Tidak ada persyaratan tertentu terkait penggunaan kapal dalam melakukan perdagangan lintas batas There are no specific requirements regarding the use of ships to carry out cross-border trade

Rawan kejahatan transnasional, karena minimnya pengawasan dan banyaknya pintu masuk di kedua negara minim pengawasan / Prone to transnational crime, due to the lack of supervision and too many entrances in both countries

Nilai perdagangan lintas batas tidak dibatasi besaran nilainya /There are no maximum restrictions for cross-border trading values

Perdagangan lintas batas hanya dilakukan oleh pemegang kartu Pas Lintas Batas /Cross-border trading activities can only be carried out by special crossborder resident card holders

PLB merupakan surat keterangan khusus bagi warga yang tinggal di wilayah batas negara dan melakukan aktivitas pelintas batas di wilayah perbatasan / $P L B$ is a special card for citizens who live in the border areas and conduct border crossing activities in the border areas

Mulai ada transaksi perdagangan (bukan dalam bentuk barter) /There began trading activities (buying and selling) not with a barter system

Dapat keluar-masuk Indonesia - Malaysia di seluruh wilayah perbatasan IPLB

$1970-2006$ holders can still go in and out of Indonesia - Malaysia in all border areas

Tidak ada persyaratan tertentu terkait penggunaan kapal dalam melakukan perdagangan lintas batas /There are no special requirements regarding the use of ships used in cross-border trading

Sudah ada payung hukum / There is already a legal basis for crossborder trading activities

Rawan kejahatan transnasional, karena minimnya pengawasan dan banyaknya pintu masuk di kedua negara minim pengawasan /Prone to transnational crime, due to the lack of supervision and too many entrances in both countries

Sudah ada persyaratan / There are already requirements

Nilai perdagangan lintas batas dibatasi besaran nilainya hanya 600 RM (senilai Rp. 2 juta) per orang per trip jika melalui laut dan 600 RM per orang per bulan jika melalui darat The value of cross-border trade is limited in value to only 600 RM (worth Rp. 2 million) per person per trip if by sea and 600 RM per person per month if by land

Pada tahun 1994 dibuat kesepakatan pada tingkat ASEAN, tentang perdagangan tradisional yang dilakukan di wilayah perbatasan negara-negara di ASEAN (launching BRUNEI DARUSSALAM - INDONESIA - MALAYSIA -PHILIPPINES - EAST ASEAN GROWTH AREA (BIMP-EAGA)) /In 1994 an agreement was made at the ASEAN level, agreement related to traditional trade conducted in the border regions of ASEAN countries (launching BRUNEI DARUSSALAM - INDONESIA MALAYSIA - PHILIPPINES - EAST ASEAN GROWTH AREA (BIMP-EAGA)))

$2009-2011$

Wacana meninjau ulang Border Trade Agreement 1970, tapi belum ada kesepakatan terhadap materi BTA yang akan direvisi / The discourse reviewed the Border Trade Agreement 1970, but there was no agreement on the BTA material to be revised 


\section{Lanjutan Tabel 1/Continue Tabel1}

\begin{tabular}{|c|c|}
\hline $\begin{array}{c}\text { Periode/Period } \\
\text { Payung Hukum/Legal Based } \\
\text { Persyaratan tertentu /Special } \\
\text { Requirements) }\end{array}$ & Keterangan/Information \\
\hline 2014 & $\begin{array}{l}\text { Ratifikasi implementasi BTA dalam aturan hukum nasional (UU tentang } \\
\text { Perdagangan) /Ratification of the implementation of border trade agreements } \\
\text { in national law (in the Law on Trade) }\end{array}$ \\
\hline $\begin{array}{l}\text { UU No.7 Th.2014 /Law number } 7 \\
\text { of } 2014\end{array}$ & $\begin{array}{l}\text { Diberlakukannya persyaratan hanya pada penduduk di wilayah lintas batas } \\
\text { yang dapat melakukan transaksi lintas batas, pintu keluar masuk Indonesia } \\
\text { ke Sabah (Malaysia) hanya dari Nunukan, dan tidak berlaku lagi PLB Sebatik } \\
\text { - Tawau IEnactment of requirements only for residents in cross-border areas } \\
\text { who can conduct cross-border transactions, Indonesian entrances to Sabah } \\
\text { (Malaysia) only from Nunukan, and no longer cross-border posts for the } \\
\text { Sebatik-Tawau border region) }\end{array}$ \\
\hline 2016 & $\begin{array}{l}\text { April 2016, pemerintah kerajaan Sabah menutupan jalur perdagangan } \\
\text { tradisional lintas batas, dengan larangan kapal kayu merapat di Pelabuhan } \\
\text { Tawau /In April 2016, the Sabah royal government closed down traditional } \\
\text { cross-border trade routes, and imposed a ban on wooden vessels to dock at } \\
\text { the Tawau Port }\end{array}$ \\
\hline \multirow[t]{3}{*}{$\begin{array}{l}\text { 2017-saat ini (2018) } \\
\text { (2017-Recently (2018)) }\end{array}$} & $\begin{array}{l}\text { Peninjauan ulang Border Trade Agreement 1970/ Review the Border Trade } \\
\text { Agreement } 1970\end{array}$ \\
\hline & $\begin{array}{l}\text { Februari 2018, terjadi larangan penggunaan kapal kayu untuk merapat di } \\
\text { Pelabuhan Tawau (February 2018, there began a ban for wooden ships to } \\
\text { dock at Tawau Port) }\end{array}$ \\
\hline & $\begin{array}{l}\text { Hingga saat ini, traditional trade masih bisa dilakukan dengan mengacu juga } \\
\text { pada kesepakatan BIMP-EAGA } 1994 \text { /Until now, traditional trade can still be } \\
\text { done by referring to the } 1994 \text { BIMP-EAGA agreement }\end{array}$ \\
\hline
\end{tabular}

Sumber: Berbagai sumber diolah oleh penulis, 2018/ Source: Various sources processed by the author, 2018.

Kondisi perubahan kebijakan seperti yang tertera dalam Tabel 1 disebabkan oleh aktivitas perekonomian masyarakat perbatasan yang sangat intensif. Kepentingan kedaulatan di wilayah perbatasan, terutama kedaulatan dari sisi ekonomi, membuat kedua pemerintahan membuat kebijakan khusus dan banyak perubahan kebijakan dengan tujuan perbaikan tata kelola kegiatan perekonomian di wilayah perbatasan Indonesia-Malaysia. Menurut Rudiatin (2018), dalam aktivitas ekonomi masyarakat perbatasan Sebatik yang terintegrasi dengan pasar negara lain dipengaruhi jaringan perdagangan yang telah terbentuk puluhan tahun; dan realitas sosial kegiatan ekonomi di Sebatik juga mengarah pada gejala integrasi ekonomi. Selanjutnya, munculnya kelompok bisnis dan kegiatan perdagangan akan menghasilkan lapangan kerja, menciptakan kekayaan, berkontribusi terhadap pendapatan pajak, dan merangsang pembangunan infrastruktur seperti transportasi (Christy \& Dassie, 2000)

Kegiatan perdagangan lintas batas menguntungkan para pedagang di kedua sisi perbatasan. Ini memberikan kesempatan bagi pedagang untuk mendapatkan pasar baru, sumber pasokan, modal, tenaga kerja dan teknologi, meskipun jenis peluang yang diterima dipengaruhi oleh tingkat perkembangan ekonomi kedua perbatasan. Menurut Blatter 2000, perdagangan lintas batas berkontribusi pada perkembangan ekonomi suatu daerah. Faktanya, kegiatan ini membawa mereka keluar dari lingkaran setan kemiskinan (Damon \& Jeuring, 2009; Muzvidziwa, 2001).

Berdasarkan hasil penelitian Siburian (2012), para pelaku usaha lintas negara di wilayah Sebatik dan mitra dagang di Tawau berasal dari etnis yang sama, Sulawesi Selatan; kesamaan etnis ini menjadi modal dalam membangun jaringan perdagangan. Kesamaan etnis pelaku usaha lintas negara di Sebatik dengan mitra dagang di Tawau menghilangkan kekhawatiran untuk melakukan perdagangan lintas negara. Menurut Saleh (2015), perantau Bugis yang mayoritas menjadi bagian tak terpisahkan dari dinamika kehidupan sosial masyarakat yang hidup di Pulau Sebatik. Eksistensi perantau Bugis di Pulau Sebatik dengan lebih fokus pada kemampuan perantau Bugis dalam menciptakan dan mengelola sumber-sumber ekonomi yang dibarengi dengan kemampuan membangun relasi, 
baik ekonomi maupun sosial sebagai upaya untuk partisipasi aktif dalam pembangunan di Pulau Sebatik.

Transaksi yang dilakukan oleh warga Sebatik di Tawau juga mengakibatkan modal uang yang mengalir ke Malaysia begitu tinggi, sehingga dari sisi ekonomi dapat dikategorikan sebagai pelarian modal yang mengakibatkan kerugian bagi Sebatik secara khusus dan Indonesia secara umum. Padahal modal yang lari itu seharusnya dapat diinvestasikan kembali di dalam negeri untuk membangun perekonomian Kabupaten Nunukan. Untuk mencegah larinya modal ke Malaysia, pemerintah perlu lebih memperhatikan ketersediaan barang-barang yang dibutuhkan oleh warga Sebatik dengan harga khusus dan warga di perbatasan lain secara berkesinambungan, karena dengan demikian, orientasi warga Sebatik dan di perbatasan lain untuk membeli barang kebutuhanannya dari negara jiran dapat dicegah. Sia-sia menghimbau warga Sebatik untuk mengutamakan barang kebutuhan hidup yang diproduksi di dalam negeri sementara ketersediaan barang tersebut sangat langka dan kalaupun ada relatif lebih mahal dibandingkan barang yang didatangkan dari Tawau (Siburian, 2012).

Pada tahun 2013, terdapat perubahan kebijakan pencabutan pas lintas batas jalur Sebatik-Tawau yang dilakukan oleh pemerintah Malaysia. Berdasarkan hasil penelitian Amalia (2018) terdapat beberapa hal pokok berkaitan dengan pencabutan Pas Lintas Batas (PLB) oleh pemerintah Malaysia secara sepihak dengan alasan infrastruktur transportasi kapal yang tidak sesuai dengan standar keamanan internasional, antara lain adanya pertimbangan keuntungan dari berkurangnya penyalahgunaan PLB di jalur Sebatik-Tawau, peningkatan PAD Tawau yang diperoleh dari biaya retribusi yang sangat besar di pelabuhan baru Tawau serta kerugian yang kemudian diterima oleh Malaysia maupun Indonesia sebagai dampak pencabutan PLB seperti peningkatan perdagangan narkoba (Drugs Trafficking) dan terhambatnya aktivitas pendistribusian dan perdagangan barang dari Tawau ke Sebatik maupun sebaliknya. Penundaan pemberian izin PLB Sebatik-Tawau oleh pemerintah Malaysia setelah tersedianya kapal sesuai dengan standar yang ditetapkan oleh Malaysia merupakan salah satu strategi yang diterapkan Malaysia dalam upaya untuk mengaktifkan kegiatan perlintasan maupun perdagangan di pelabuhan baru Ferry Terminal
Tawau yang baru dibuka pada akhir tahun 2016 . Berdasarkan kebijakan baru yang disepakati kedua negara untuk mengalihkan rute penyeberangan dari Sebatik-Tawau menjadi Nunukan-Tawau, seharusnya tidak ada lagi aktvitas perdagangan lintas batas yang terjadi antara masyarakat di perbatasan kedua negara, namun kenyataannya meskipun PLB Sebatik-Tawau telah dicabut dan penyeberangan resmi hanya ada di Nunukan, hingga saat ini masyarakat yang berada di perbatasan Sebatik maupun Tawau masih melakukan aktivitas lintas batas baik berdagang maupun sekedar berkunjung melalui dermaga-dermaga hingga jalurjalur tikus yang berada di Sebatik-Tawau tanpa mengindahkan kesepakatan yang telah ditetapkan.

Hasil penelitian Anuar \& Harun (2019), juga menyatakan bahwa kebijakan pencabutan pas lintas batas jalur sebatik - tawau merupakan kebijakan keamanan yang ditempuh oleh pemerintah Sabah yang memberikan dampak negatif pada aktivitas perekonomian di Tawau.

Peran pemerintah Indonesia dalam terhadap kebijakan politik di wilayah perbatasan Indonesia - Malaysia dapat digambarkan dalam Gambar 1. Pada kondisi saat ini, persyaratan yang diterapkan dalam perdagangan lintas batas tetap disesuaikan dengan kesepakatan pertemuan kelompok kerja Sosek Malindo antara negara bagian Sabah dan Provinsi Kalimantan Utara yang dilakukan rutin tiap tahun.

Pelaksanaan hasil dari kelompok kerja Sosek Malindo harus dilihat sebagai salah satu strategi optimalisasi perdagangan lintas batas yang berorientasi pada kesejahteraan dan kesetaraan (Kurnia, 2017).

\section{DINAMIKA BORDER CROSS AGREEMENT (BCA) DAN BORDER TRADE AGREEMENT (BTA) ANTARA INDONESIA DAN MALAYSIA DAN PENGARUH SKPT SEBATIK}

Implementasi kerjasama Sosek Malindo dapat meningkatkan Confidence Building Measure (CBMs) dan tingkat kesejahteraan masyarakat di wilayah perbatasan. Meskipun kondisi perkembangan kerjasama Sosek Malindo juga harus memperhatikan hambatan yang muncul pada proses pelaksanaan (Fahrozi, Sutimo \& Thomas, 2019). Pembentukan Sosek Malindo pada tahun 1984 dianggap belum memberikan hasil yang signifikan bagi perkembangan kawasan perbatasan Malaysia dan Indonesia, meskipun 
pembentukan rezim internasional kerjasama antara Malaysia dan Indonesia dibentuk untuk menjaga kawasan perbatasan yang dimiliki kedua negara dan ditujukan untuk mensejahterakan masyarakat di kawasan tersebut. Hambatan pada proses pelaksanaan Sosek Malindo berasal dari dua faktor yang berbeda, yaitu dari faktor organisasional yang berhubungan dengan struktur dalam Sosek Malindo, dan dari faktor non-organisasional yang berhubungan dengan dinamika perkembangan Sosek Malindo sebagai rezim (Putri, 2016).

Perkembangan perundingan pada tingkat pemerintahan Provinsi Kalimantan Utara (Kaltara) dengan pemerintahan negeri Sabah hingga Agustus 2018 dilakukan terutama terkait dengan perkembangan usaha sektor perikanan antarnegara. Isu pembahasan dalam pertemuan dilakukan terkait kerjasama pemanfaatan sumber daya perikanan oleh industri perikanan oleh kedua negara dengan melihat peluang dari adanya persamaan dari segi sosio-ekonomi dan budaya yang menjadi kekuatan dalam memajukan industri perikanan. Pembangunan SKPT di Pulau Sebatik dianggap sebagai bentuk dukungan pemerintah pusat Indonesia dalam meningkatkan posisi tawar Indonesia (dalam hal ini Provinsi Kaltara) dalam melakukan perundingan kerjasama lanjutan dalam kelompok kerja Sosek Malindo dengan Malaysia (dalam hal ini Pemerintah Negeri Sabah).
Pembangunan SKPT di Sebatik menjadi salah satu bukti political will dari pemerintah Indonesia lebih memperhatikan wilayah perbatasan. Hal ini sesuai dengan pendapat dari Fadjri (2018) yang menyatakan bahwa pemerintah harus mempunyai political will dengan membuat berbagai program pembangunan berbasis kepulauan yang mampu meningkatkan kesejahteraan masyarakat di pulau-pulau terluar Indonesia, karena selama itu tidak dilakukan, maka tidak ada jaminan bahwa pulau-pulau terluar Indonesia bebas dari berbagai ancaman negaranegara lain.

Materi yang menjadi pembahasan, antara lain terkait dengan pertukaran informasi teknologi pemanfaatan hasil perikanan di Sabah perlu dilakukan agar dapat memaksimalkan pemanfaatan hasil perikanan. Indonesia melihat Malaysia (Sabah) merupakan pasar terdekat dan potensial dalam pemasaran hasil perikanan dari wilayah perairan di Kalimantan Utara. Penjajakan peluang kerjasama terdapat pada usaha budidaya udang dan kepiting bakau, selain terkait dengan peluang pasar dari udang dan kepiting bakau, juga peluang untuk mengatasi permasalahan kekurangan benur udang dan belum ada usaha pembenihan kepiting bakau. Ke depan, diharapkan nantinya dapat dipenuhi oleh hatchery udang di Sabah dan selanjutnya juga dapat ditindaklanjuti dengan alih teknologi terkait pembenihan udang dari wilayah Sabah;

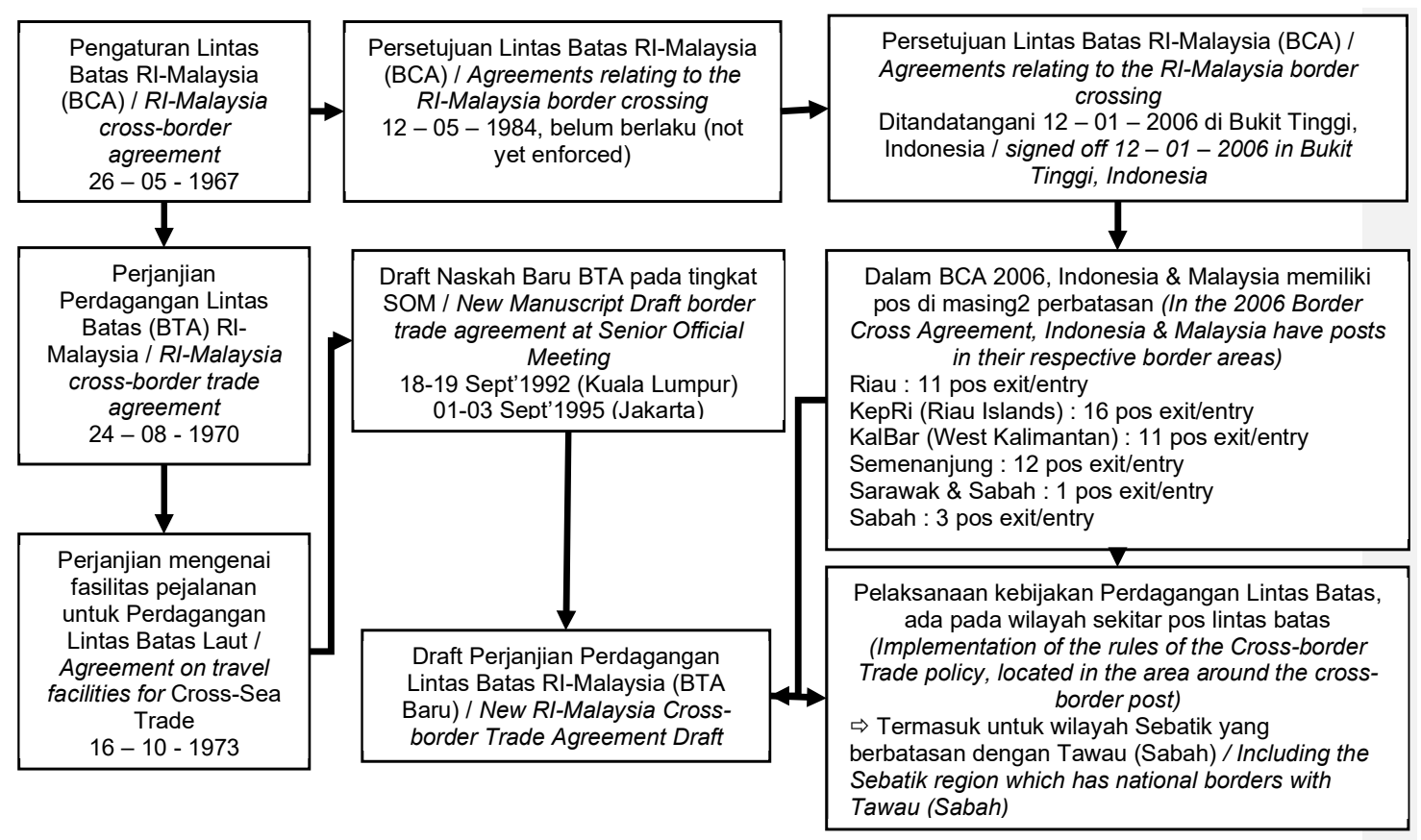

Gambar 1. Skema BCA dan BTA antara Indonesia - Malaysia.

Figure 1. The BCA and BTA Scheme between Indonesia - Malaysia. 
dan terkait komoditas rumput laut kering yang merupakan salah satu peluang produk dari Kalimantan Utara yang dapat dipasarkan pada usaha pengolahan rumput laut di Malaysia.

Setelah dimulainya implementasi program pembangunan SKPT di Pulau Sebatik, komunikasi tetap dilakukan secara aktif dalam koridor kerjasama Sosek Malindo, agar tidak terjadi beda pemahaman dalam penerapan kebijakan Border Crossing Agreement (BCA) saat ini. Keberadaan kesepakatan (MoU) antara pemerintah Indonesia dan Malaysia yang mengatur Border Crossing Agreement (BCA), menetapkan Nunukan ditetapkan sebagai Entry dan Exit Point, namun jika Sebatik ditetapkan sebagai Entry dan Exit Point maka pihak Malaysia berpendapat perjanjian tersebut harus ditinjau ulang; namun hal ini ditanggapi oleh Penanggung Jawab SKPT Sebatik, bahwa Sebatik merupakan bagian dari Nunukan, jadi tetap tidak akan mengubah content dari materi perjanjian tersebut.

Permasalahan terkait isu pengangkutan di laut, dalam hal penggunaan kapal kecil (NCSS), terdapat tiga tingkat permasalahan dikarenakan melibatkan banyak negara; yaitu pada tingkat Putra Jaya-Malaysia, tingkat BIMP EAGA, dan tingkat ASEAN, terkait dengan pemindahan ikan, barter trade dan pengangkutan barang lainnya akan ditindaklanjuti dan diputuskan pada tingkat ASEAN. Terkait pemasalahan kegiatan ekspor impor antara Indonesia-Malaysia, akan dilakukan pengawasan dokumen yang diperlukan dan harus dipahami bersama agar memudahkan prosedur ekspor impor untuk dapat dipatuhi dan dijalankan dalam rangka mewujudkan kegiatan perikanan yang terintegrasi. Dokumen diwajibkan dilengkapi sebelum hasil perikanan khususnya yang hidup diimpor atau diekspor. Untuk solusi sementara, terkait pengangkutan hasil perikanan, solusi sementara penggunaan kapal kayu yang sudah terdaftar di Tawau digunakan untuk mengangkut hasil perikanan dengan memenuhi kelengkapan dokumen kapal yang akan dibicarakan lebih detail dan diketahui oleh kedua negara. Pengawasan akan diperketat dan akan mempersiapkan kapal yang sesuai standar kapal internasional (pembinaan kapal besar).

Pembangunan SKPT di Pulau Sebatik diperkirakan akan menjadi pusat kegiatan perikanan yang baru di wilayah perbatasan Indonesia-Malaysia, dan kondisi ini juga akan membuat para pelaku usaha perikanan kembali beradaptasi dengan upaya perbaikan tata kelola usaha perikanan di wilayah Sebatik. Kebijakan pembangunan SKPT di Sebatik ini juga memberikan dampak positif pada delegasi Indonesia dalam perundingan kerjasama Sosek Malindo.

\section{IMPLIKASI KEBIJAKAN}

Berdasarkan pada pembahasan di atas, Pembangunan SKPT Sebatik akan mempengaruhi kerjasama Sosek Malindo secara positif. Pertama, pembangunan SKPT Sebatik akan menjadikan Sebatik sebagai pusat perekonomian baru di wilayah perbatasan Indonesia akan memindahkan sebagian kegiatan perekonomian (dalam hal ini perdagangan komoditas hasil perikanan) tidak hanya berpusat pada Tawau (Malaysia) sebagai pasar utama, tapi juga menciptakan pasar baru dengan memunculkan peluang mengundang konsumen untuk langsung membeli produk perikanan di Sebatik.

Kedua, Pembangunan SKPT di Pulau Sebatik dianggap sebagai bentuk dukungan pemerintah pusat Indonesia dalam meningkatkan posisi tawar Indonesia (dalam hal ini Provinsi Kaltara) dalam melakukan perundingan kerjasama lanjutan dalam kelompok kerja Sosek Malindo dengan Malaysia (dalam hal ini Pemerintah Negeri Sabah). Peningkatan posisi tawar tersebut membaik dikarenakan sebelum adanya SKPT Sebatik, masyarakat beranggapan pemerintah Indonesia membiarkan mereka memiliki ketergantungan penuh dengan pasar Tawau untuk menjual hasil-hasil perikanan di wilayah Sebatik.

Sementara pihak Malaysia pun merasa pembangunan SKPT di Pulau Sebatik diperkirakan akan menjadi pusat kegiatan perikanan yang baru di wilayah perbatasan Indonesia-Malaysia, dan jika berkembang, maka akan menjadi pesaing dari pasar di Tawau. Kondisi ini juga akan membuat para pelaku usaha perikanan kembali beradaptasi dengan upaya perbaikan tata kelola usaha perikanan di wilayah Sebatik.

Implikasi kebijakan dari analisis ini yang dapat direkomendasikan sebagai berikut:

1. Perjanjian sosek malindo perlu disosialisasikan secara detail oleh pemerintah Propinsi Nunukan kepada para pengusaha sektor perikanan apabila ada perubahanperubahan sehubungan dengan perdagangan produk perikanan.

2. Keterlibatan unit pengelola SKPT Sebatik diperkuat dalam pertemuan-pertemuan 
dan perubahan perjanjian sosek Malindo sehingga tujuan pembangunan ekonomi sebagaimana tujuan SKPT sebatik sebagai sentra kelautan dan perikanan terpadu mampu meningkatkan kualitas hasil tangkapan perikanan nelayan Sebatik dan meningkatkan kesejahteraannya melalui perdagangan hasil laut ke pasar domestik maupun ke pasar luar negeri yaitu Tawau, Malaysia.

3. Apabila terdapat kendala dalam pengembangan SKPT Sebatik, hal tersebut akan ada dibahas pada perundingan kebijakan sosek Malindo. Contohnya adalah pelarangan kapal kayu ke Tawau oleh pemerintah Malaysia. Pada saat yang sama, kapal-kapal di Sebatik mayoritas merupakan kapal kayu. Hal ini perlu kebijakan khusus yang dapat dituangkan dan diakomodasi dalam kerjasama sosek malindo tersebut.

\section{UCAPAN TERIMA KASIH}

Terima kasih penulis ucapkan pada semua pihak yang telah menjadi teman diskusi dalam membahas topik tulisan terkait perbatasan, bapak Armen Zulham yang telah memberikan arahan terkait topik penulisan, dan pada Balai Besar Riset Sosial Ekonomi Kelautan dan Perikanan (BBRSEKP) yang telah memberikan kesempatan melakukan penelitian pada lokasi yang dibahas dalam tulisan ini.

\section{PERNYATAAN KONTRIBUSI PENULIS}

Penulis pertama dalam Karya Tulis IImiah ini adalah kontributor utama dan penulis kedua adalah penulis anggota dalam survei pengumpulan data, analisis maupun penulisan naskah secara keseluruhan.

\section{DAFTAR PUSTAKA}

Alihar, F. (2018). Kebijakan Pengelolaan Pulau-Pulau Terluar Di Tinjuau Dari Aspek Kependudukan. Jurnal Kebijakan Sosek KP Vol. 8 No. 1 Juni 2018: 39-51.

Alwasilah, A. C. 2011. Pokoknya Kualitatif Dasar-dasar Merancang dan Melakukan Penelitian Kualitatif. Jakarta: Pustaka Jaya. Cetakan ke-6. 284 hlm.

Anuar, A. R., \& Harun, A. (2019). Malaysia-Indonesia cross-border governance: Is there a trade-off between security and economic development? Malaysia: Journal of International Studies, 15, 21-34.
ASEAN. (2017). Joint Statement 12th Brunei Darussalam-Indonesia-Malaysia-Philippines East Asean Growth Area Summits (12th BIMP-EAGA Summits). Dilihat dari link: https://aei.um.edu. my./malaysia-asean/joint-statement-12th-bimpeaga-summit

Blatter, J. (2000). Emerging Cross-border Regions as a Step towards Sustainable Development? International Journal of Economic Development, 2(3), 402-439.

Chisty, R. D., \& Dassie, W. (2000). Enterpreneuship centered economic development: An analysis of African American entrepreneurship in the Southern BlacK Belt. Contractor Paper 00-10, TVA Rural Studies.

Damon, M., \& Jeuring, K. (2009). Informal cross-border trade as an instrument alleviating poverty. Open Society Initiative for Southern Africa, 114-118.

Direktorat Perencanaan Ruang Laut. (2016). Masterplan dan Bisnisplan Pembangunan Sentra Kelautan dan Perikanan Terpadu (SKPT) Pulau Sebatik Kabupaten Nunukan. Direktorat Perencanaan Ruang Laut. Direktorat Jenderal Pengelolaan Ruang Laut. Kementerian Kelautan dan Perikanan Tahun 2016.

Fahrozi, F., Sutimo S., Thomas G.J. (2019). Program Kelompok Kerja Sosial Ekonomi Indonesia-Malaysia (KK Sosek Malindo) di Kalimantan Barat Ditinjau dari Perspektif Diplomasi Pertahanan Indonesia. Jurnal Diplomasi Pertahanan Vol.5 No.1 April 2019. Bogor: Universitas Pertahanan Indonesia. Diunduh pada link http://jurnalprodi.idu.ac.id/index.php/ DP/article/view/364/341.

Indonesia. (2012). Undang-Undang Republik Indonesia tentang Pembentukan Provinsi Kalimantan Utara. UU RI No.20 Tahun 2012. LN No.229 TLN No.5362.

Indonesia. (2014). Undang-Undang Republik Indonesia tentang Perdagangan. UU RI No.7 Tahun 2014. LN No.45 TLN No.5512.

Kurnia, M.P. (2017). Strategi Optimalisasi Perdagangan Lintas Batas Indonesia-Malaysia Untuk Meningkatkan Kesejahteraan Masyarakat Pulau Sebatik Kabupaten Nunukan. Jurnal Supremasi Vol.7 No.1 Maret 2017. Blitar: Universitas Islam Balitar. Diunduh pada link https://ejournal. unisbablitar.ac.id/index.php/supremasi/article/ view/372.

Koespramoedyo, D., Sri H.M., Aulia J., Moris N., Amril B., \& Fauzan D. (2003). Strategi dan Model Pengembangan Wilayah Perbatasan Kalimantan. Jakarta: Direktorat Pengembangan Kawasan Khusus dan Tertinggal, Deputi Bidang Otonomi Daerah dan Pengembangan Regional. Badan Perencanaan Pembangunan Nasional (BAPPENAS). 
[MOU] Memorandum Of Understanding Between The Government Of The Republic Of Indonesia And The Government Of Malaysia In Respect Of The Common Guidelines Concerning Treatment Of Fishermen By Maritime Law Enforcement Agencies Of Malaysia And The Republic Of Indonesia. Perjanjian antara Pemerintah Indonesia dengan Pemerintah Malaysia di Bali, 27 January 2012. Unpublished.

Mira, Solihin. A., \& Tajerin. (2013). Strategi Peningkatan Ekonomi Wilayah Perbatasan Berbasis Kelautan dan Perikanan (Studi Kasus di Nanusa, Natuna, dan Nunukan). Jakarta: Jurnal Sosiokonsepsia Vol.18. No.03. September-Desember Tahun 2013. HIm. 255-277.

Muzvidziwa, V. (2001). Zimbabwe's cross-border women traders: Multiple identities and responses to new challenges. Journal of Contemporary African Studies, 19(1), 67-80. http://dx.doi. org/10.1080/02589000124044

Rahmita, P. K. (2016). Hambatan dalam Kinerja Kelompok Kerja Sosial Ekonomi Malaysia-Indonesia (KK Sosek Malindo). Yogyakarta: FISIP UGM. Skripsi. Unpublished. Diunduh pada link https://digilib.fisipol.ugm.ac.id/api/files/cd518c5bad11-4cb7-84e6-ad90010b8a74/29714413 ca 2581 cde 96 bba $58 f 1$ ec 187 bd $2140 f-$ S12016297144complete.pdf.

Rudiatin, E. (2018). Malayndonesia Integrasi Ekonomi di Perbatasan Indonesia-Malaysia: Sebatik Kalimantan Utara-Tawau Sabah. Bekasi: Bening Era Media. Cet.1.

Saleh, M. H. (2015). Dinamika Masyarakat Perbatasan (Eksistensi Perantau Bugis Di Pulau Sebatik Kalimantan Utara: Perspektif Cultural Studies). Jurnal Borneo Administrator Vol.11 No.1 Tahun 2015.

Setiawaty, A. (2018). Analisis Pencabutan Pas Lintas Batas Jalur Sebatik-Tawau. Samarinda: Universitas Mulawarman. eJournal IImu Hubungan Internasional Vol.6 No.2 HIm.375-388.

Siburian, R. (2012). Pulau Sebatik: Kawasan Perbatasan Indonesia Beraroma Malaysia. Jurnal Masyarakat dan Budaya Vol.14 No.1.

Siregar, C. N., Sutiadi R., \& Epin S. (2019). Ancaman Keamanan Nasional di Wilayah Perbatasan Indonesia: Studi Kasus Pulau Sebatik dan Tawau (Indonesia-Malaysia). Sosioglobal: Jurnal Pemikiran dan Penelitian Sosiologi Vol.4 No.1 Desember 2019.

Sudiar, S. (2014). Rezim Kerjasama Sosek Malindo Kaltim-Sabah: Mengukur Derajat Compliance Partisipan Perjanjian. Jurnal Hubungan Internasional Vol. 3 No. 1 / April 2014. HIm.33-43.
Sudiar, S. (2015). Pembangunan Wilayah Perbatasan Negara: Gambaran Tentang Strategi Pengelolaan Kawasan Perbatasan Darat di Provinsi Kalimantan Utara. Jurnal Administrative Reform, Vol.3 No.4, Oktober - Desember 2015. HIm.489-500.

Wahyuni, T. \& M. Kusumaningrum. (2016). Sisi Lain Kebijakan Pengelolaan SDA Sebatik. Policy Brief. Samarinda: Pusat Kajian Dan Pendidikan Dan Pelatihan Aparatur III LAN Samarinda. Diunduh pada link: http://pusaka.lan.go.id/ documents/58551/1824039/JFAK+0006++PB+SEBATIK/52eed 954-1fbd-4c63-b3b120d3ca3a4861 pada tanggal 24 Agustus 2018.

Warta Kementerian Perdagangan RI. (2016). Kawasan Perbatasan sebagai Pintu Ekspor Indonesia. Tajuk Utama. Ditjen PEN/MJL/58/VIII/2016 edisi Agustus. Warta Ekspor. HIm. 3-7. 